\title{
Enhanced IL-6/phosphorylated STAT3 signaling is related to the imbalance of circulating $T$ follicular helper/T follicular regulatory cells in patients with rheumatoid arthritis
}

Qian Niu, Zhuo-chun Huang, Xiao-juan Wu, Ya-xiong Jin, Yun-fei An, Ya-mei Li, Huan Xu, Bin Yang* and Lan-lan Wang ${ }^{*}$ (D)

\begin{abstract}
Background: Follicular helper T (Tfh) cells are specialized in helping B lymphocytes, which play a central role in autoimmune diseases that have a major B cell component, such as in rheumatoid arthritis (RA). Follicular regulatory $\mathrm{T}$ (Tfr) cells control the over-activation of Tfh and B cells in germinal centers. Dysregulation of Tfh cells and Tfr cells has been reported to be involved in the pathogenesis of some autoimmune diseases. However, the balance of Tfh and Tfr cells, and their roles in the development and progression of RA are still not clear.

Methods: In this study, we enrolled 44 patients with RA (20 patients with active RA and 24 patients with inactive RA) and 20 healthy controls, and analyzed the frequencies of circulating Tfh and Tfr cells, expression of programmed death-1 (PD-1), inducible co-stimulator (ICOS), intracellular IL-21, and pSTAT3 in Tfh cells, and serum levels of IL-6. The correlation among these parameters and that of Tfh or Tfr cells with disease activity were also analyzed.

Results: Patients with RA (especially active RA) had higher frequencies of Th cells, but lower percentages of Tfr cells, thereby resulting in elevated ratios of Tfh/Tfr. Expression levels of PD-1 and IL-21 in Tfh cells were higher in patients with RA than in healthy subjects, while no difference in ICOS expression was observed between patients and controls. Both pSTAT3 expression and serum IL-6 levels increased in patients with RA, and positive correlation between them was observed. Additionally, PSTAT3 expression was positively correlated with Tfh cell frequency. The Disease Activity Score in 28 joints based on C-reactive protein (DAS28-CRP) was negatively correlated with Tfr cell frequency, but was positively correlated with both Tfh/Tfr ratio and PD-1 expression.
\end{abstract}

Conclusions: Results demonstrated that enhanced IL-6/pSTAT3 signaling may contribute to promotion of Tfh cells, consequently skewing the ratio of Th to Tfr cells, which may be crucial for disease progression in RA.

Keywords: Rheumatoid arthritis, Follicular helper T cells, Follicular regulatory T cells, PD-1, ICOS, IL-21, IL-6, STAT3, DAS28-CRP

\footnotetext{
* Correspondence: yangbinhx@scu.edu.cn; wanglanlanhx@163.com

Department of Laboratory Medicine, West China Hospital, Sichuan University,

37\#, Guoxue Alley, Chengdu 610041, China
}

(c) The Author(s). 2018 Open Access This article is distributed under the terms of the Creative Commons Attribution 4.0 International License (http://creativecommons.org/licenses/by/4.0/), which permits unrestricted use, distribution, and reproduction in any medium, provided you give appropriate credit to the original author(s) and the source, provide a link to the Creative Commons license, and indicate if changes were made. The Creative Commons Public Domain Dedication waiver (http://creativecommons.org/publicdomain/zero/1.0/) applies to the data made available in this article, unless otherwise stated. 


\section{Background}

Rheumatoid arthritis (RA) is a chronic inflammatory autoimmune disease, characterized by symmetrical inflammation of synovium, which mainly affects the peripheral diarthrodial joints, leading to progressive destruction of articular cartilage and bones, culminating in severe pain and disability [1]. The pathogenesis of RA is complicated and not yet fully elucidated; however, both innate mechanism and highly evolved adaptive immune functions seem to operate simultaneously to create and propagate the inflammatory reactions attacking the joints $[2,3]$. The robust production of autoantibodies, including rheumatoid factor (RF) and anti-cyclic citrullinated peptides antibodies (ACPA), is a crucial factor in RA pathophysiology, that can lead to immune-complex deposition and the subsequent recruitment and activation of inflammatory leukocytes in the joints [4]. Usually, it is preceded by activation, somatic diversification, and affinity maturation of auto-reactive B lymphocytes, which occur in the germinal centers (GC) [5]. In these processes, follicular helper $\mathrm{T}$ (Tfh) cells are the principal $\mathrm{CD}^{+} \mathrm{T}$ helper cell subpopulation, providing essential help to B cells [6], whereas regulatory $\mathrm{T}$ cells (Tregs) function to control $\mathrm{B}$ cell responses and play a critical role in the establishment of self-tolerance.

Tfh cells occur predominantly in the B cell follicles, playing a key role in GC formation, B cell development and maturation, and immunoglobulin class switching. They can be distinguished from other subsets of differentiated $\mathrm{CD}^{+}{ }^{+} \mathrm{T}$ cell lineages by the high expression of $\mathrm{C}-\mathrm{X}-\mathrm{C}$ chemokine receptor type 5 (CXCR5), programmed death-1 (PD-1), inducible co-stimulator (ICOS), CD40 ligand (CD40L), and secretion of interleukin-21 (IL-21) [7, 8]. Accumulating evidence has shown that dysregulation of Tfh cells and IL-21 could result in disordered autoimmunity, contributing to various autoimmune diseases, such as systemic lupus erythematosus (SLE) and ankylosing spondylitis (AS) $[9,10]$. The high frequency of circulating Tfh cells (which could imply enhanced cell differentiation) is also reported to correlate with disease activity in patients with new-onset RA [11]. Tfh cells are localized in lymphoid follicles, making it difficult to study these cells. However, a recent study has shown that human peripheral blood $\mathrm{CD} 4^{+} \mathrm{CXCR}^{+}$cells have functional properties similar to Tfh cells [12]. Circulating CXCR ${ }^{+} \mathrm{T}$ cells, which secrete high levels of IL-21 to promote B cell differentiation into plasma cells, are more capable of facilitating $\mathrm{B}$ cell maturation and humoral responses than CXCR5 ${ }^{-}$T cells [13]. Thus, circulating Tfh cells are crucial for the pathogenesis of autoimmune diseases [14].

Tfh cell differentiation involves multiple micro-environmental factors; one clinical study showed that secretion of IL- 6 by plasmablasts resulted in Tfh cell differentiation [15]. IL-6 is involved in human Tfh cell differentiation; after binding to its receptor, it phosphorylates the signal transducer and activator of transcription 3 (STAT3), which is essential for dimerization and nuclear translocation [16]. IL-6 is an inflammatory cytokine with an important role in the pathogenesis of RA and our previous study [17] had shown that serum IL-6 level obviously increased in patients with RA. In this study, we hypothesized that the circulating Tfh cells may be elevated via the IL-6/STAT3 signal pathway.

Enhanced GC reactions must be regulated to prevent the excessive production of auto-antibodies, and an increasing number of studies have found that follicular regulatory $\mathrm{T}$ (Tfr) cells-a specialized population of Tregs that are primarily located in germinal centers-can specifically suppress Tfh and B cells to control the GC reaction $[18,19]$. Tfr cells share the phenotypic characteristics of both Tfh cells and classical Tregs, simultaneously expressing Foxp3 and CXCR5, as well as PD-1 and ICOS [18-20], thereby playing an opposing role with Tfh cells in the regulation of humoral immunity [21]. The immune homeostasis of Tfh and Tfr cells is reported to be disrupted in the peripheral blood of patients with autoimmune diseases such as SLE, myasthenia gravis (MG), and multiple sclerosis (MS) [22-24]. However, few studies have investigated the role of Tfh/Tfr imbalance in the pathogenesis of RA in detail. The role of Tfr cells and their relationship with other T cell subsets in the abnormal immune responses of RA remain to be elucidated.

Therefore, we determined the frequencies of circulating $\mathrm{CD}^{+} \mathrm{CXCR}^{+} \mathrm{Foxp}^{-}$Tfh and $\mathrm{CD} 4^{+} \mathrm{CXCR} 5^{+} \mathrm{Foxp}^{+}$ Tfr cells, and the expression of PD-1, ICOS, intracellular IL-21 and phosphorylated STAT3 (pSTAT3) in Tfh cells in patients with RA and corresponding healthy controls (HCs). The correlation of Tfh and Tfr cells with disease activity in RA was investigated.

\section{Methods}

This prospective study was performed in accordance with a protocol approved by the Ethics Committees of West China Hospital. Written informed consent was obtained from all participants.

\section{Participants}

Forty-four patients with RA were enrolled in this study. All patients met the American College of Rheumatology (ACR)/European League Against Rheumatism (EULAR) classification criteria (2010) [25]. The exclusion criteria were as follows: subjects with other autoimmune diseases or tumors, plasma exchanges or thymectomy prior to the study, and with acute inflammation in the preceding 4 weeks. Disease activity was assessed by the Disease Activity Score in 28 joints based on C-reactive protein (DAS28-CRP). Routine measurements were made of CRP, $\mathrm{RF}$, and ACPA (screened by electro-chemiluminescence 
Table 1 Characteristics of the patients with RA and the healthy controls

\begin{tabular}{|c|c|c|c|c|}
\hline Characteristics & $\begin{array}{l}\text { Active RA } \\
(n=20)\end{array}$ & $\begin{array}{l}\text { Inactive RA } \\
(n=24)\end{array}$ & $\begin{array}{l}\mathrm{HCs} \\
(n=20)\end{array}$ & $P$ value \\
\hline Age $\left(\right.$ years) ${ }^{a}$ & $46(38-57)$ & $47(40-53)$ & $48(39-55)$ & $>0.05$ \\
\hline Female $(n(\%))$ & $16(80.0)$ & $18(75.0)$ & $15(75.0)$ & $>0.05$ \\
\hline Symptom duration (months) ${ }^{a}$ & $10(5-60)$ & $15(8-70)$ & ND & $0.015^{\mathrm{b}}$ \\
\hline Swollen joint count (out of 28$)^{a}$ & $5(3-8)$ & $2(1-5)$ & ND & $0.039^{b}$ \\
\hline Tender joint count (out of 28$)^{a}$ & $6(2-9)$ & $4(1-7)$ & ND & $0.027^{b}$ \\
\hline $\mathrm{CRP}(\mathrm{mg} / \mathrm{L})^{\mathrm{a}}$ & $6.5(2.1-13.8)$ & $4.0(1.4-9.2)$ & ND & $0.031^{b}$ \\
\hline DAS28-CRP (3) ${ }^{a}$ & $4.2(3.5-5.6)$ & $1.8(1.0-2.8)$ & ND & $0.001^{b}$ \\
\hline ACPA $(I U / m l)^{a}$ & $451.9(222.2-1208.0)$ & $129.6(6.0-322.6)$ & ND & $0.006^{\mathrm{b}}$ \\
\hline $\mathrm{RF}(\mathrm{IU} / \mathrm{ml})^{\mathrm{a}}$ & $132.0(30.73-267.3)$ & $23.8(19.0-75.1)$ & ND & $0.027^{b}$ \\
\hline $\mathrm{ACPA} \geq 17 \mathrm{IU} / \mathrm{ml}(n(\%))$ & $18(90.0)$ & $17(70.8)$ & ND & $>0.05^{b}$ \\
\hline $\mathrm{RF} \geq 20 \mathrm{IU} / \mathrm{ml}(n(\%))$ & $15(75.0)$ & $17(70.8)$ & ND & $>0.05^{b}$ \\
\hline $\mathrm{ACPA} \geq 17 \mathrm{IU} / \mathrm{ml}+\mathrm{RF} \geq 20 \mathrm{IU} / \mathrm{ml}(n(\%))$ & $14(70.0)$ & $16(66.7)$ & ND & $>0.05^{b}$ \\
\hline $\mathrm{ACPA} \leq 17 \mathrm{IU} / \mathrm{ml}+\mathrm{RF} \leq 20 \mathrm{IU} / \mathrm{ml}(n(\%))$ & $3(15.0)$ & $4(16.7)$ & ND & $>0.05^{b}$ \\
\hline
\end{tabular}

$R A$ rheumatoid arthritis, HC healthy controls, CRP C-reactive protein, DAS28 Disease Activity Score $28, A C P A$ anti-cyclic citrullinated peptide antibody,

$R F$ rheumatoid factor, $N D$ not determined

${ }^{\mathrm{a}}$ Data are presented as median (IQR)

${ }^{b}$ Patients with active RA vs. patients with inactive RA, Mann-Whitney $U$ test

immunoassay (ECLIA) using the Cobas e601, Roche Pharma Itd., Reinach, Switzerland). The patient group was compared to a group of 20 age-matched and sex-matched HCs. The characteristics of the patients and HCs are shown in Table 1.

\section{Cell preparation}

The experiments were carried out within 1 hour of obtaining the heparinized venous blood samples from the participants. For analysis of intracellular IL-21, $500 \mu \mathrm{l}$ of whole blood from every sample was cultured in a complete culture medium (Roswell Park Memorial Institute (RPMI) 1640 supplemented with $10 \%$ heat-inactivated fetal calf serum) for $5 \mathrm{~h}$, in the presence of phorbol 12-myristate 13-acetate (PMA, $50 \mathrm{ng} / \mathrm{ml}$, Sigma-Aldrich, St. Louis, MO, USA), ionomycin, calcium salt $(1 \mu \mathrm{g} / \mathrm{ml}$, Sigma-Aldrich), and monensin (BD GolgiStop $^{\mathrm{Tm}}, 1 \mu \mathrm{g} / \mathrm{ml}$, BD Biosciences, San Diego, CA, USA). The incubators were set at $37{ }^{\circ} \mathrm{C}$ under a $5 \% \mathrm{CO}_{2}$ environment. The remaining unstimulated whole blood was aliquoted into tubes $(50 \mu \mathrm{l}$ each) for further analysis of PD-1, ICOS, Tfr, and pSTAT3.

\section{Flow cytometry}

The monoclonal antibodies targeting human CD3 (clone SP34-2, peridin chlorophyll protein (PerCP)), CD4 (clone SK3, fluorescein isothiocyanate (FITC)), IL-21 (clone 3A3-N2.1, phycoerythrin (PE)), and pSTAT3 (clone 4/ P-STAT3, PE) were all purchased from BD Biosciences; PD-1 (clone MIH4, PE), ICOS (clone ISA-3, PE), and Foxp3 (clone 236A/E7, PE) were all from eBioscience (San
Diego, CA, USA); and CXCR5 (clone J252D4, APC) was from BioLegend (San Diego, CA, USA). Appropriate isotype controls were used to enable correct compensation and confirm antibody specificity. For PD-1 and ICOS analysis, $50 \mu \mathrm{l}$ of unstimulated cells were incubated with surface-staining antibodies (CD3-PerCP, CD4-FITC, CXCR5- allophycocyanin (APC), and PD-1-PE or ICOS$\mathrm{PE})$ at $4{ }^{\circ} \mathrm{C}$ for $30 \mathrm{~min}$ in the dark. To detect intracellular

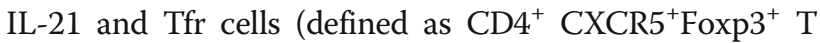
cells), $50 \mu \mathrm{l}$ stimulated (for IL-21 detection) and $50 \mu \mathrm{l}$ unstimulated cells (for Tfr detection) were incubated with surface-staining antibodies (CD3-PerCP, CD4-FITC, and CXCR5-APC) at $4{ }^{\circ} \mathrm{C}$ for $30 \mathrm{~min}$ in the dark. Surface-stained cells were fixed and permeabilized with a Foxp3 Staining Set (eBioscience) and stained with PE-conjugated IL-21 or PE-conjugated Foxp3. For pSTAT3 analysis, $50 \mu \mathrm{l}$ of unstimulated cells were incubated with surface-staining antibodies (CD4-FITC and CXCR5-APC) at $4{ }^{\circ} \mathrm{C}$ for $30 \mathrm{~min}$ in the dark. Then, $20 \mu \mathrm{g} / \mathrm{ml}$ recombinant human (rh) IL-6 (MN 550071) was added to stimulate the $50-\mu \mathrm{l}$ surface-stained whole blood for $30 \mathrm{~min}$ at $37{ }^{\circ} \mathrm{C}$ in the dark. Stimulated cells were lysed and fixed with Lyse/ Fix buffer (BD Biosciences) at $37^{\circ} \mathrm{C}$ for $10 \mathrm{~min}$ and then permeabilized in Perm Buffer III (BD Biosciences) for $30 \mathrm{~min}$ on ice. Finally, the cells were stained with PE-conjugated pSTAT3 (pY705) and PerCP-conjugated $\mathrm{CD} 3$ at $4{ }^{\circ} \mathrm{C}$ for $30 \mathrm{~min}$ in the dark, after washing twice with BD Pharmingen stain BSA buffer (BD Biosciences).

Stained cells were run on a FACSCanto II cytometer (BD Biosciences), and the data were analyzed using FACSDiva software (BD Biosciences). 


\section{Determination of serum IL- 6}

Serum samples were collected on the day of flow cytometry and stored at $-80{ }^{\circ} \mathrm{C}$ before detection. The concentration of serum IL- 6 was quantified by ECLIA using the Cobas e601 (Roche) instrument, following the standard operating procedure (SOP) of the Department of Laboratory Medicine in West China Hospital of Sichuan University. Results are expressed as picograms per milliliter.

\section{Statistical analysis}

Summary statistics (number and percentage or median and interquartile range (IQR)) were used to describe the participants' baseline characteristics. Numerical results were expressed as mean \pm SEM or median (IQR), and analyzed using the IBM SPSS software (version 22.0; IBM Corp., Armonk, NY, USA). The significance level was set at 0.05 for all statistical tests. The data were initially analyzed using analysis of variance or the Kruskal-Wallis $\mathrm{H}$ test. If a significant result was observed, Holm-Sidak's test or Dunn's test was used to detect inter-group differences. Spearman's correlation coefficient with the two-tailed $P$ value was calculated to test for correlation between pairs of continuous variables.

\section{Results}

Frequencies of circulating Th and Tfr cells in patients with RA and the HCs

To investigate the status of circulating Tfh and Tfr cells, we detected the frequencies of $\mathrm{CD} 4^{+} \mathrm{CXCR} 5^{+} \mathrm{Foxp} 3^{-} \mathrm{Tfh}$ and $\mathrm{CD} 4^{+} \mathrm{CXCR} 5^{+}$Foxp $3^{+}$Tfr cells, which were gated from $\mathrm{CD} 3^{+} \mathrm{CD} 4^{+} \mathrm{T}$ cells in a flow cytometry analysis of patients with RA and HCs (Additional file 1: Figure S1A, B). According to the DAS28-CRP score, patients with RA were divided into two groups: the active RA group $(n=20)$ with DAS28-CRP $>3.2$ and the inactive RA group $(n=24)$ with DAS28-CRP $\leq 3.2$.
Frequencies of circulating Tfh cells in patients with active RA $(25.0 \pm 1.6 \%)$ were significantly higher than those either in patients with inactive RA $(18.4 \pm 1.1 \%)$ or in $\mathrm{HCs}$ $(18.2 \pm 1.3 \%) \quad(P<0.01$, Fig. 1a). Compared to the $\mathrm{HC}$ group $(2.0 \pm 0.2 \%)$, frequencies of peripheral Tfr cells were significantly lower in both the active RA $(0.9 \pm 0.1 \%)$ and inactive RA groups $(1.2 \pm 0.2 \%)(P<0.05)$. However, there was no obvious difference between the two RA groups $(P>0.05)$ (Fig. 1b). In addition, the active RA group had the highest ratios of Tfh cells to Tfr cells (36.5 $\pm 5.6 \%)$, followed by the inactive RA group $(23.6 \pm 3.2 \%)$ and the control group $(10.2 \pm 0.8 \%)(P<0.05$, Fig. $1 c)$.

Expression of PD-1, ICOS, intracellular IL-21 or PSTAT3 in circulating Tfh cells of patients with RA and the HCs

$\mathrm{CD} 4{ }^{+} \mathrm{CXCR} 5{ }^{+} \mathrm{T}$ cell gating allowed us to investigate the expression of PD-1, ICOS, IL-21, or pSTAT3 (Additional file 2: Figure S2A-D). As shown in Fig. 2, the expression of PD-1 and IL-21 in either the active RA group (31.5 $\pm 2.1 \%$ and $4.9 \pm 0.6 \%$, respectively) or inactive RA group (26.5 \pm $2.5 \%$ and $4.5 \pm 0.5 \%$, respectively) was significantly higher than that in the HCs $(13.4 \pm 0.8 \%$ and $2.7 \pm 0.3 \%$, respectively) $(P<0.05$, Fig. $2 \mathrm{a}$ and $\mathrm{c})$, while there was no difference observed in ICOS expression in circulating CD4 ${ }^{+} \mathrm{CXCR} 5^{+}$ $\mathrm{T}$ cells among the three groups (active RA, $15.5 \pm 2.3 \%$; inactive RA, $13.2 \pm 1.2 \%$; HCs, $12.3 \pm 1.0 \%$; $P>0.05$, Fig. $2 b$ ). The expression of pSTAT3 in $\mathrm{CD} 4^{+} \mathrm{CXCR} 5^{+}$Tfh cells was highest in the active RA group $(51.3 \pm 3.4 \%)$, followed by that in the inactive RA group $(39.3 \pm 1.9 \%)$ and the control group $(29.7 \pm 1.7 \%)(P<0.05$, Fig. $2 d)$.

Concentration of serum IL- 6 in patients with RA and the HCs Significantly elevated serum IL- 6 levels were observed in patients with RA compared with the control group (1.7 (1.6-2.6) $\mathrm{pg} / \mathrm{ml}, P<0.001)$, and the difference in levels in the two RA groups (active RA group, 27.6
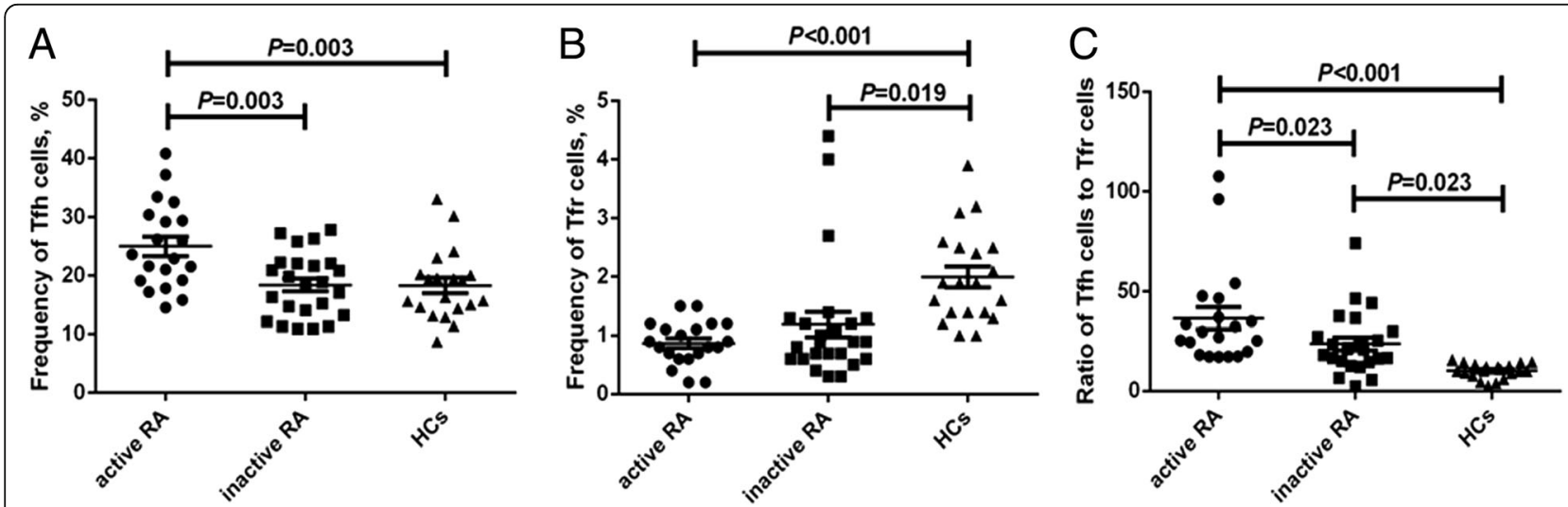

Fig. 1 Frequencies of circulating follicular helper $T$ (Tfh) and follicular regulatory $T$ (Tfr) cells in patients with rheumatoid arthritis (RA) and the healthy controls ( $\mathrm{HCs}$ ). Horizontal bars indicate the mean and error bars represent the SEM. The frequencies of circulating CD4 ${ }^{+} \mathrm{CXCR} 5^{+}$Foxp ${ }^{-}{ }^{-}$Tfh cells (a) and $\mathrm{CD} 4^{+} \mathrm{CXCR5^{+ }}$ Foxp3 ${ }^{+} \mathrm{Tfr}$ cells (b) were investigated gating on CD4 ${ }^{+} \mathrm{T}$ cells in patients with active RA (circles), patients with inactive RA (squares), and the HCs (triangles). c Ratios of Tfh to Tfr cells in patients with active RA (circles), patients with inactive RA (squares), and the HCs (triangles) 

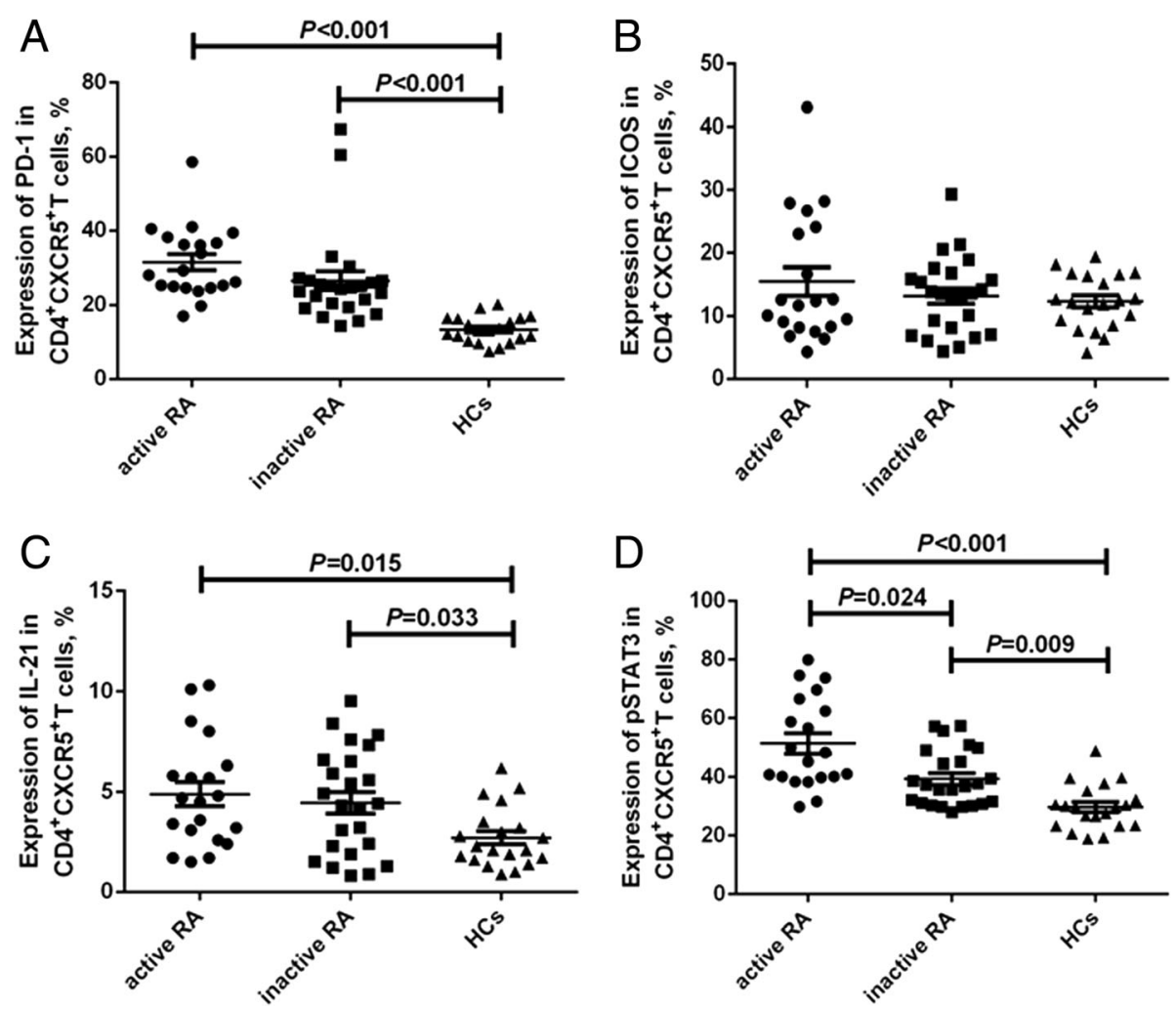

Fig. 2 Expression of programmed death-1 (PD-1), ICOS, intracellular IL-21 or pSTAT3 in circulating CD4 ${ }^{+}$CXCR5 ${ }^{+}$follicular helper T (Tfh) cells of patients with rheumatoid arthritis (RA) and the healthy controls (HCs). Horizontal bars indicate the mean and error bars represent the SEM. The expression of PD-1 (a), inducible co-stimulator (ICOS) (b), intracellular IL-21 (c) or phosphorylated STAT3 (pSTAT3) (d) was investigated gating on $\mathrm{CD}^{+} \mathrm{CXCR5^{+ }}$ T cells in patients with active RA (circles), patients with inactive RA (squares), and the HCs (triangles)

(12.0-51.4) $\mathrm{pg} / \mathrm{ml}$; inactive $\mathrm{RA}$ group, $7.7(3.2-15.0)$ $\mathrm{pg} / \mathrm{ml}$ ) was also significant $(P<0.01)$ (Fig. 3, IL-6 levels are shown on a logarithmic scale).

Correlation between pSTAT3 expression and serum IL-6 level There was positive correlation between pSTAT3 expression and serum IL-6 level ( $r=0.425, P=0.005$, Fig. 4$)$.

\section{Correlation between pSTAT3 expression and circulating} Tfh or Tfr cell frequency

As shown in Fig. 5, there was positive correlation between pSTAT3 expression and circulating Tfh cell frequency $(r=0.477, P=0.001)$. However, there was no correlation between pSTAT3 expression and either Tfr frequency or $\mathrm{Tfh} / \mathrm{Tfr}$ ratio $(P>0.05)$.

Correlation between the frequencies of circulating Tfh or Tfr cells and the DAS28-CRP

The frequency of circulating Tfr cells was negatively correlated with the DAS28-CRP $(r=-0.337, P=0.025$, Fig. 6a), while the ratio of Tfh cells to Tfr cells was positively correlated with the DAS28-CRP $(r=0.510, P<$ 0.001 , Fig. 6b). However, there was no correlation between Tfh frequency and the DAS28-CRP $(P>0.05)$.

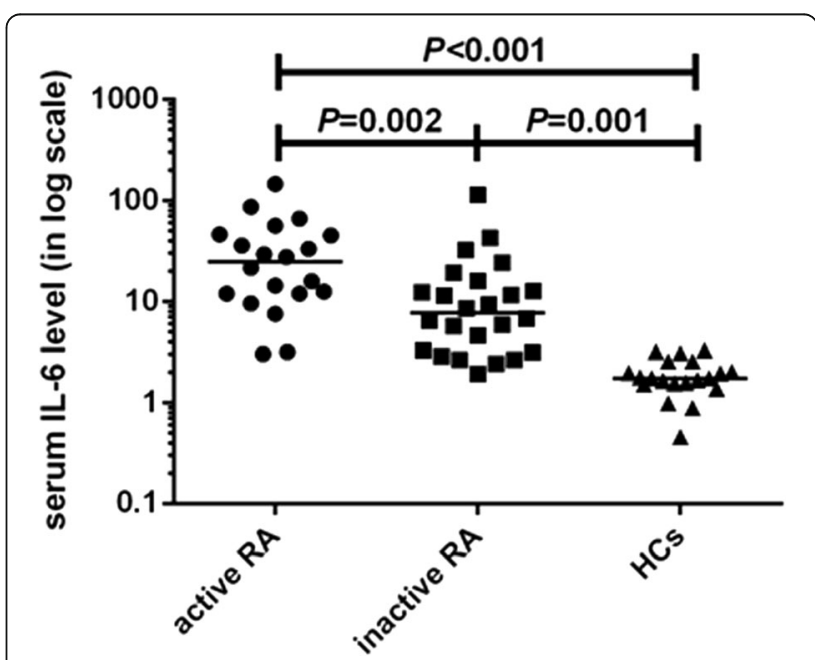

Fig. 3 Serum IL-6 levels in patients with active rheumatoid arthritis (RA) (circles), patients with inactive RA (squares), and the healthy controls (HCs) (triangles). IL-6 levels (pg/ml) are shown in a log scale. Horizontal bars indicate the median 


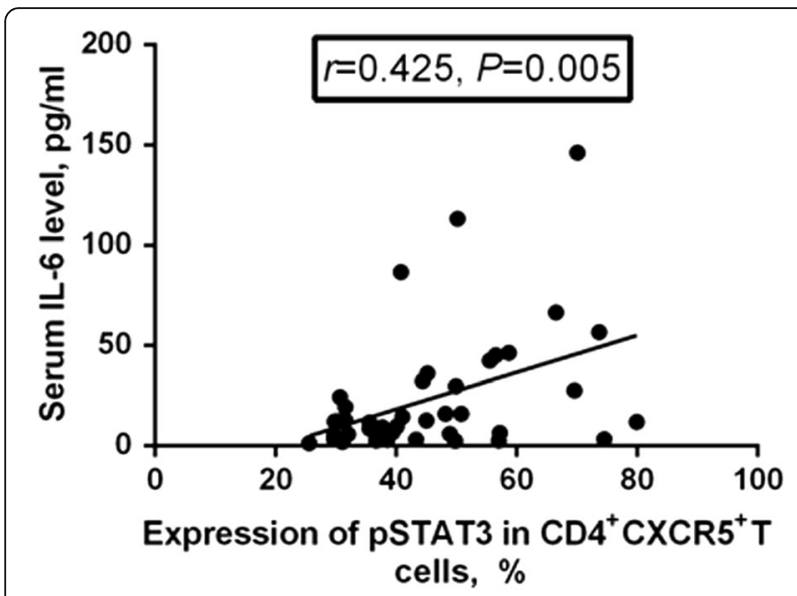

Fig. 4 Correlation between phosphorylated STAT3 (pSTAT3) expression and serum IL-6 level. The expression of pSTAT3 in CD4 ${ }^{+} \mathrm{CXCR5}{ }^{+}$follicular helper $T$ (Tfh) cells was positively correlated with serum IL-6 level $(r=0.425, P=0.005)$

Correlation between PD-1, ICOS, or IL-21 expression and the DAS28-CRP

PD-1 expression was positively correlated with the DAS28-CRP $(r=0.323, P=0.033$, Fig. 7$)$, while neither ICOS expression nor IL-21 expression were correlated with the DAS28-CRP $(P>0.05)$.

\section{Discussion}

Blood $\mathrm{CD}^{+} \mathrm{CXCR}^{+} \mathrm{T}$ cells may, to some extent, represent the circulating counter-part of memory Tfh cells [13], and additional molecular markers, i.e., PD-1 and ICOS, could be used to identify the activation status of Tfh cells [6]. PD-1 supports the survival of B cells and formation of plasma cells by interacting with PD-L1 and

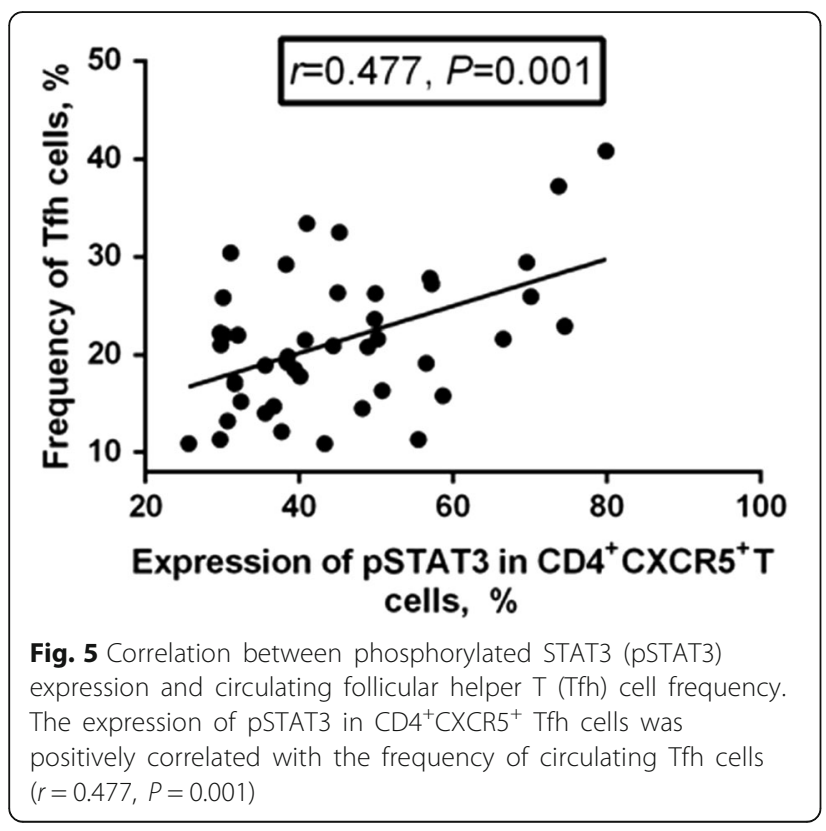

PD-L2 on GC B cells [26], whereas ICOS can positively regulate humoral responses and IL-21 production [27]. In this study, we revealed that in both the active and inactive RA groups, the expression of PD-1 in Tfh cells was significantly higher than that in the $\mathrm{HC}$ group, and was positively correlated with the DAS28-CRP score. Although the expression of ICOS in Tfh cells was a little higher in patients with RA than in $\mathrm{HCs}$, the difference was not significant. These findings suggest that enhanced expression of PD-1, but not ICOS, in Tfh cells might be involved in the development and progression of RA, and be of potential value as an indicator and therapeutic target of RA.

However, the inhibitory function of PD-1 on T cells and $\mathrm{B}$ cells, which is important in peripheral tolerance, cannot be ignored [28]. The up-regulated expression of PD-1 in Tfh cells in patients with RA, as observed in this study, might result from spontaneous compensatory regulation of the immune system so that PD $-1^{+}$Tfh cells can negatively regulate autoimmune responses in patients with RA. Actually, increased expression of PD-1 has been detected in human synovial tissue and fluid in RA, which might reflect the negative feedback regulation of inflammation in the joints [29]. Therefore, elucidation of the influence of enhanced PD-1 expression in Tfh cells in the development of RA would require further study.

Tfh cells secrete IL-21, a cytokine that has been found to not only promote naive $\mathrm{T}$ cell differentiation into potent $\mathrm{B}$ helper cells, but also to promote $\mathrm{GC}$ B cell responses through CD-40 L/CD-40 interaction [14]. Moreover, Tfh cells regulate B cell proliferation, differentiation, and antibody production via the secretion of IL-21 $[13,30]$. To further understand the ability of peripheral Tfh cells to produce IL-21, we detected the expression of intracellular IL-21 in Tfh cells in patients with RA. The results showed that the expression of IL-21 in Tfh cells was significantly higher in patients with RA than in HCs, but was not correlated with the DAS28-CRP, indicating the augmented capacity of circulating Tfh cells to secrete IL-21 in patients with RA and increased potency to promote B cell proliferation, differentiation, and antibody production. Reportedly, exposure of $\mathrm{CD}^{+}{ }^{+} \mathrm{T}$ cells to IL-21 drives them to differentiate into a Tfh cell subset partly through modulation of the expression of CXCR5 and CCR7 by IL-21 in an autocrine manner $[31,32]$. However, there was no correlation between IL-21 expression with Tfh cell frequency in the present study. Actually, in addition to IL-21, numerous other cytokines, including IL-6, IL-12, and TGF- $\beta$, also reportedly contribute to Tfh cell differentiation [33].

Tfr cells express Foxp3 and have been identified to be involved in regulating the GC reaction [19]. Given that Tfh and Tfr cells have opposite roles in regulating GC responses, balance of their activities is critical for 

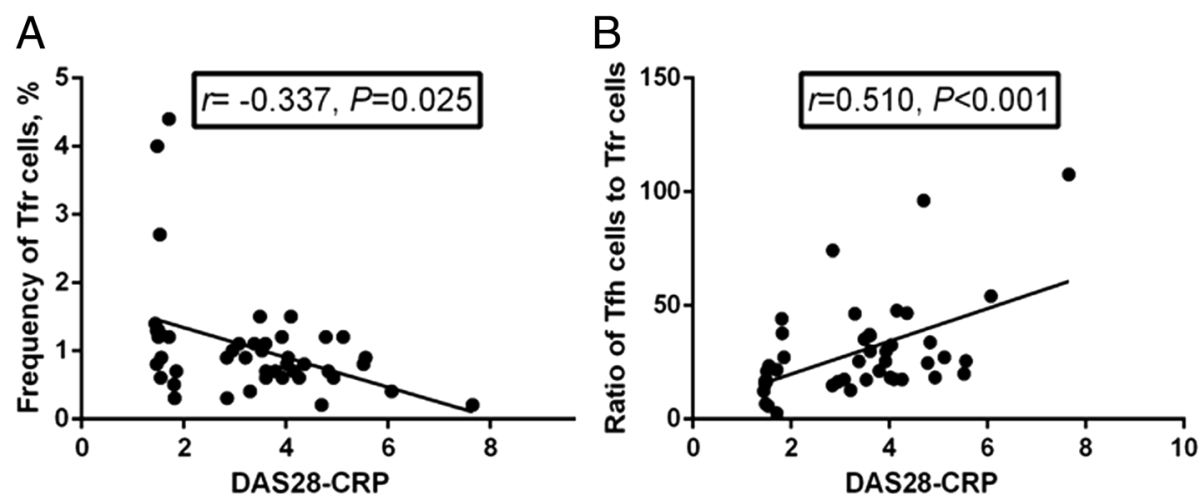

Fig. 6 Correlation between circulating follicular helper T (Tfh) or follicular regulatory T (Tfr) cell frequency and the Disease Activity Score in 28 joints based on C-reactive protein (DAS28-CRP). The circulating Tfr cell frequency was negatively correlated with DAS28-CRP $(r=-0.337, P=0.025)$ (a), while the Tfh/Tfr ratio was positively correlated with DAS28-CRP $(r=0.510, P<0.001)$ (b)

immune homeostasis. An impaired Tfr compartment could enhance Tfh activity, resulting in the expansion of auto-reactive B cells and autoantibody production [34]. The dysregulation of Tfh and Tfr cells has been reported to contribute to the development of many autoimmune diseases, including experimental autoimmune myasthenia gravis (EAMG) [35] and multiple sclerosis [24]. In this study, we presented evidence of imbalances between the circulating Tfh cell subsets and Tfr cells in patients with RA. Inconsistent with the report by Pandya JM et al. [36], we found a significant decrease in Tfr cell frequency in patients with RA, while Pandya JM et al. did not identify a significant difference in Tfr cell frequency between patients with early RA and HCs. The inconsistency between the results of Pandya JM et al. and ours might be attributed to the different symptom duration in the patients with RA enrolled in this study compared to

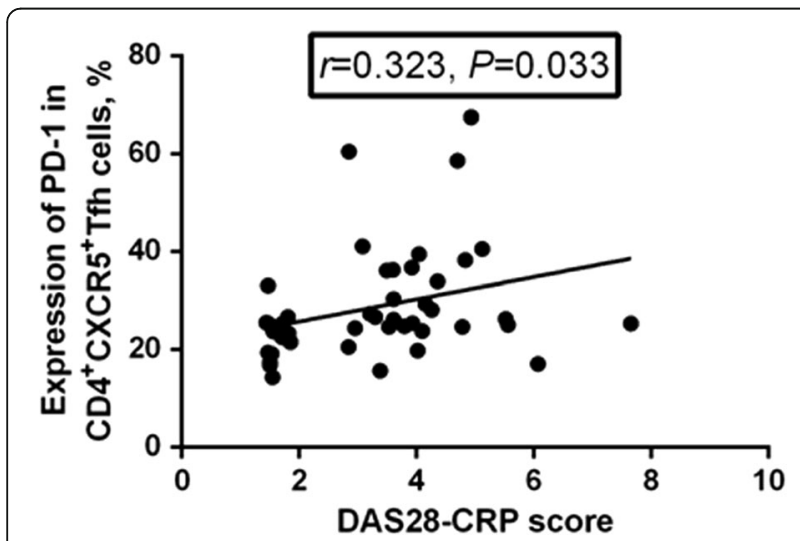

Fig. 7 Correlation between programmed death-1 (PD-1) expression and the Disease Activity Score in 28 joints based on C-reactive protein (DAS28-CRP). The expression of PD-1 in CD4 ${ }^{+}$CXCR5 ${ }^{+}$follicular helper $T$ (Tfh) cells was positively correlated with DAS28-CRP $(r=0.323, P=0.033)$ those in the previous study. The median symptom duration in all included patients with RA was 13 months in this study, whereas it was 6 months (suggesting a very early stage of RA) in Pandya's study.

Patients with active RA had marginally lower Tfr cell frequency than patients with inactive RA, but the difference was not significant. In spite of this, negative correlation was identified between the frequency of circulating Tfr cells and disease activity (DAS28-CRP). With the increased proportion of Tfh subsets and decreased percentage of Tfr cells, ratios of Tfh/Tfr were significantly increased in patients with RA, although no differences in the ratios were found between patients with active RA and those with inactive RA. In addition, Tfh/Tfr ratio was positively correlated with the DAS28-CRP. These results suggested that the imbalance of Tfh and Tfr cells might contribute to the breakdown of self-tolerance in RA, thus serving as a potential target for therapy and a meaningful tool for disease evaluation.

STAT3 has been reported as a positive regulator of Tfh cell differentiation. Mice with STAT3 deficiency or humans with functional STAT3 impairment have been reported to have reduced numbers of Tfh cells and an attenuated B cell response [37, 38]. Phosphorylation of STAT3, a marker of the activation of STAT3 pathways, has been reported to be activated mainly by IL-6, which induces Tfh differentiation and IL-21 production [38, 39]. In the present study, we observed significantly up-regulated expression of PSTAT3 in peripheral Tfh cells, as expected after being stimulated with IL-6, and significantly increased serum IL-6, especially in patients with active RA. Meanwhile, there was positive correlation between pSTAT3 expression and serum IL-6, which was consistent with the research of Deng et al. [40]. Further analysis revealed that PSTAT3 expression was positively correlated with circulating Tfh cell frequency, but there was no 
correlation between pSTAT3 expression and Th//Tr ratio. Taken together, these results demonstrated that elevated serum IL-6 might be pivotal in promoting the imbalance of Tfh and Tfr cells in patients with RA, via activation of the STAT3 signaling pathway by induction of pSTAT3, so as to participate in the development and progression of RA.

Of note, although positive correlation was identified between the expression of pSTAT3 and circulating Tfh cell frequency, there was no correlation between pSTAT3 expression and PD-1, ICOS, or IL-21 expression. These results suggested that the up-regulated expression of pSTAT3 might mainly contribute to the increase in Tfh cell frequency but had no obvious effects on the expression of PD-1, ICOS, or IL-21 in Tfh cells in RA.

Despite all the important findings of this study, there are some limitations as well. In addition to PD-1 and ICOS, the chemokine receptors CXCR3 and CCR6 are also commonly used markers that define Tfh subsets, namely Tfh1, Tfh2, and Tfh17 [41]. These Tfh subsets are reported to exert different helper functions to B cells, which makes their exploration highly significant; these will be pursued in our future studies.

\section{Conclusions}

To the best of our knowledge, this is the first report to demonstrate the imbalance of Tfh subsets and Tfr cells in patients with RA. Increased Tfh cell percentages and decreased Tfr cell frequencies resulted in elevated $\mathrm{Tfh} /$ Tfr ratios. Augmented capacity of the circulating Tfh cells to secrete IL-21 and imbalance of Tfh/Tfr cells might contribute to the breakdown of self-tolerance in $\mathrm{RA}$, and thus serve as a potential target for therapy and a meaningful tool for disease evaluation. Enhanced IL-6/ pSTAT3 signaling might be potent in promoting the $\mathrm{Tfh} / \mathrm{Tfr}$ imbalance, mainly via promotion of Th cells, and the immunopathogenesis of RA.

\section{Additional files}

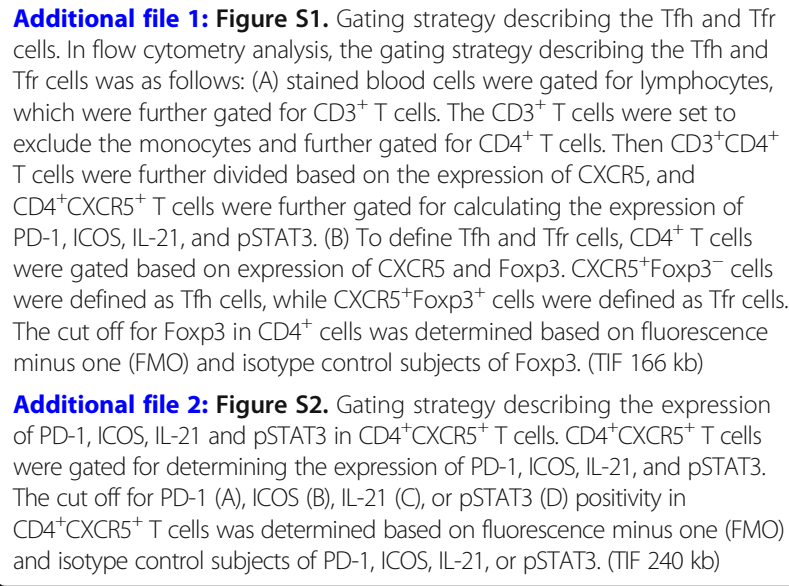
cells. In flow cytometry analysis, the gating strategy describing the Th and Tfr cells was as follows: (A) stained blood cells were gated for lymphocytes, which were further gated for $\mathrm{CD}^{+} \mathrm{T}$ cells. The $\mathrm{CD}^{+} \mathrm{T}$ cells were set to exclude the monocytes and further gated for $\mathrm{CD}^{+} \mathrm{T}$ cells. Then $\mathrm{CD}^{+} \mathrm{CD}^{+}$ $T$ cells were further divided based on the expression of CXCR5, and $\mathrm{CD}^{+}{ }^{+} \mathrm{CXCR5}^{+} \mathrm{T}$ cells were further gated for calculating the expression of PD-1, ICOS, IL-21, and pSTAT3. (B) To define Th and Tfr cells, CD4 ${ }^{+} T$ cells were gated based on expression of CXCR5 and Foxp3. CXCR5 ${ }^{+}$Foxp3 $^{-}$cells were defined as Tfh cells, while $\mathrm{CXCR}^{+} \mathrm{Foxp}^{+}$cells were defined as Tfr cells. The cut off for Foxp3 in $\mathrm{CD}^{+}$cells was determined based on fluorescence minus one (FMO) and isotype control subjects of Foxp3. (TIF $166 \mathrm{~kb}$ )

Additional file 2: Figure S2. Gating strategy describing the expression of PD-1, ICOS, IL-21 and pSTAT3 in CD4 ${ }^{+}$CXCR5 ${ }^{+} T$ cells. CD4 ${ }^{+}$CXCR5 ${ }^{+} T$ cells were gated for determining the expression of PD-1, ICOS, IL-21, and PSTAT3. The cut off for PD-1 (A), ICOS (B), IL-21 (C), or PSTAT3 (D) positivity in $\mathrm{CD}^{+}{ }^{+} \mathrm{CXCR}^{+} \mathrm{T}$ cells was determined based on fluorescence minus one (FMO) and isotype control subjects of PD-1, ICOS, IL-21, or pSTAT3. (TIF $240 \mathrm{~kb}$ )

\section{Abbreviations}

ACPA: anti-citrullinated peptide antibodies; ACR: American College of Rheumatology; AS: Ankylosing spondylitis; CD40L: CD40 ligand; CRP: C-reactive protein; CXCR5: C-X-C chemokine receptor type 5; DAS28: Disease Activity Score in 28 joints; EAMG: Experimental autoimmune myasthenia gravis; EULAR: European League Against Rheumatism; GC: Germinal centers; HCs: Healthy controls; ICOS: Inducible co-stimulator; IL-21: Interleukin-21; IQR: Interquartile range; MG: Myasthenia gravis; MS: Multiple sclerosis; PD-1: Programmed death-1; PSTAT3: Phosphorylated signal transducer and activator of transcription 3; RA: Rheumatoid arthritis; RF: Rheumatoid factor; SLE: Systemic lupus erythematosus; Tfh cell: Follicular helper T cell; Tfr cell: Follicular regulatory T cell; Tregs: Regulatory T cells

\section{Acknowledgements}

We thank the patients for donating samples, and the hospital staff for making the study possible. This research was sponsored by the National Natural Science Foundation of China (number 81501816, 81772258, 81301496, 81601830).

\section{Funding}

This research was sponsored by the National Natural Science Foundation of China (number 81501816, 81772258, 81601830, 81301496). The funders had no role in study design, data collection and analysis, decision to publish, or preparation of the manuscript.

\section{Availability of data and materials}

All data generated or analyzed during this study are included in this published article and the supplemental data.

\section{Authors' contributions}

QN participated in the design of the study, data analysis and interpretation, statistical analysis, and writing of the manuscript. ZCH participated in the design of the research, statistical analysis, and writing of the manuscript. XJW participated in the performance of the research and revising of the manuscript. YXJ and YFA participated in the performance of the research and statistical analysis. YML and HX participated in the collection of samples and clinical data. BY and LLW participated in study design and revising of the manuscript. All authors have approved the final version of the manuscript.

\section{Ethics approval and consent to participate}

This prospective study was performed in accordance with a protocol approved by the Ethics Committees of West China Hospital. Written informed consent was obtained from all participants.

\section{Consent for publication}

Not applicable.

\section{Competing interests}

The authors declare that they have no competing interests.

\section{Publisher's Note}

Springer Nature remains neutral with regard to jurisdictional claims in published maps and institutional affiliations.

Received: 15 April 2018 Accepted: 31 July 2018

Published online: 29 August 2018

\section{References}

1. Mclnnes IB, Schett $G$. The pathogenesis of rheumatoid arthritis. N Engl J Med. 2011;365(23):2205-19.

2. Klareskog L, Catrina Al, Paget S. Rheumatoid arthritis. Lancet (London, England). 2009;373(9664):659-72.

3. Firestein GS. The disease formerly known as rheumatoid arthritis. Arthritis Res Ther. 2014;16(3):114.

4. Conigliaro P, Chimenti MS, Triggianese P, Sunzini F, Novelli L, Perricone C, Perricone R. Autoantibodies in inflammatory arthritis. Autoimmun Rev. 2016;15(7):673-83.

5. Moschovakis GL, Bubke A, Friedrichsen M, Falk CS, Feederle R, Forster R. T cell specific Cxcr5 deficiency prevents rheumatoid arthritis. Sci Rep. 2017;7(1):8933.

6. Ueno H. T follicular helper cells in human autoimmunity. Curr Opin Immunol. 2016;43:24-31. 
7. Liu X, Nurieva Rl, Dong C. Transcriptional regulation of follicular T-helper (Tfh) cells. Immunol Rev. 2013;252(1):139-45.

8. Fazilleau N, Mark L, McHeyzer-Williams LJ, McHeyzer-Williams MG. Follicular helper T cells: lineage and location. Immunity. 2009;30(3):324-35.

9. Le Coz C, Joublin A, Pasquali JL, Korganow AS, Dumortier H, Monneaux F. Circulating TFH subset distribution is strongly affected in lupus patients with an active disease. PLoS One. 2013;8(9):e75319.

10. Xiao F, Zhang HY, Liu YJ, Zhao D, Shan YX, Jiang YF. Higher frequency of peripheral blood interleukin 21 positive follicular helper T cells in patients with ankylosing spondylitis. J Rheumatol. 2013;40(12):2029-37.

11. Wang J, Shan Y, Jiang Z, Feng J, Li C, Ma L, Jiang Y. High frequencies of activated $B$ cells and $T$ follicular helper cells are correlated with disease activity in patients with new-onset rheumatoid arthritis. Clin Exp Immunol. 2013;174(2):212-20.

12. Vinuesa CG, Cook MC. Blood relatives of follicular helper T cells. Immunity. 2011;34(1):10-2.

13. Morita R, Schmitt N, Bentebibel SE, Ranganathan R, Bourdery L, Zurawski G, Foucat E, Dullaers M, Oh S, Sabzghabaei N, et al. Human blood CXCR5(+)CD4(+) T cells are counterparts of T follicular cells and contain specific subsets that differentially support antibody secretion. Immunity. 2011;34(1):108-21.

14. Yu M, Cavero V, Lu Q, Li H. Follicular helper T cells in rheumatoid arthritis. Clin Rheumatol. 2015;34(9):1489-93.

15. Chavele KM, Merry E, Ehrenstein MR. Cutting edge: circulating plasmablasts induce the differentiation of human T follicular helper cells via IL-6 production. J Immunol (Baltimore, Md : 1950). 2015;194(6):2482-5.

16. Aggarwal BB, Kunnumakkara AB, Harikumar KB, Gupta SR, Tharakan ST, Koca C, Dey S, Sung B. Signal transducer and activator of transcription-3, inflammation, and cancer: how intimate is the relationship? Ann N Y Acad Sci. 2009;1171:59-76.

17. Niu Q, Cai B, Huang ZC, Shi YY, Wang LL. Disturbed Th17/Treg balance in patients with rheumatoid arthritis. Rheumatol Int. 2012;32(9):2731-6.

18. Linterman MA, Pierson W, Lee SK, Kallies A, Kawamoto S, Rayner TF, Srivastava M, Divekar DP, Beaton L, Hogan JJ, et al. Foxp3+ follicular regulatory T cells control the germinal center response. Nat Med. 2011;17(8):975-82.

19. Gong $Y$, Tong J, Wang S. Are follicular regulatory T cells involved in autoimmune diseases? Front Immunol. 2017;8:1790.

20. Sage PT, Sharpe AH. T follicular regulatory cells. Immunol Rev. 2016;271(1): 246-59.

21. Sage PT, Sharpe AH. T follicular regulatory cells in the regulation of B cell responses. Trends Immunol. 2015;36(7):410-8.

22. Xu B, Wang S, Zhou M, Huang Y, Fu R, Guo C, Chen J, Zhao J, Gaskin F, Fu $S M$, et al. The ratio of circulating follicular $T$ helper cell to follicular $T$ regulatory cell is correlated with disease activity in systemic lupus erythematosus. Clin Immunol (Orlando, Fla). 2017;183:46-53.

23. Wen $Y$, Yang B, Lu J, Zhang J, Yang H, Li J. Imbalance of circulating CD4(+)CXCR5(+)FOXP3(+) Tfr-like cells and CD4(+)CXCR5(+)FOXP3(-) Tfh-like cells in myasthenia gravis. Neurosci Lett. 2016;630:176-82.

24. Dhaeze T, Peelen E, Hombrouck A, Peeters L, Van Wijmeersch B, Lemkens N, Lemkens $P$, Somers V, Lucas S, Broux B, et al. Circulating follicular regulatory $T$ cells are defective in multiple sclerosis. J Immunol (Baltimore, Md : 1950). 2015;195(3):832-40.

25. Aletaha D, Neogi T, Silman AJ, Funovits J, Felson DT, Bingham CO 3rd, Birnbaum NS, Burmester GR, Bykerk VP, Cohen MD, et al. 2010 Rheumatoid arthritis classification criteria: an American College of Rheumatology/ European league against rheumatism collaborative initiative. Arthritis Rheum. 2010;62(9):2569-81.

26. Yao S, Chen L. PD-1 as an immune modulatory receptor. Cancer J (Sudbury, Mass). 2014;20(4):262-4.

27. Bauquet AT, Jin H, Paterson AM, Mitsdoerffer M, Ho IC, Sharpe AH, Kuchroo VK. The costimulatory molecule ICOS regulates the expression of C-Maf and IL-21 in the development of follicular Thelper cells and TH-17 cells. Nat Immunol. 2009;10(2):167-75.

28. Riley JL, June $\mathrm{CH}$. The CD28 family: a T-cell rheostat for therapeutic control of T-cell activation. Blood. 2005;105(1):13-21.

29. Raptopoulou AP, Bertsias G, Makrygiannakis D, Verginis P, Kritikos I, Tzardi M, Klareskog L, Catrina Al, Sidiropoulos P, Boumpas DT. The programmed death 1 /programmed death ligand 1 inhibitory pathway is up-regulated in rheumatoid synovium and regulates peripheral T cell responses in human and murine arthritis. Arthritis Rheum. 2010;62(7):1870-80.
30. Bryant VL, Ma CS, Avery DT, Li Y, Good KL, Corcoran LM, de Waal MR, Tangye SG. Cytokine-mediated regulation of human B cell differentiation into Ig-secreting cells: predominant role of IL-21 produced by CXCR5+ T follicular helper cells. J Immunol (Baltimore, Md: 1950). 2007;179(12):8180-90.

31. Vogelzang A, McGuire HM, Yu D, Sprent J, Mackay CR, King C. A fundamental role for interleukin-21 in the generation of T follicular helper cells. Immunity. 2008;29(1):127-37.

32. Nurieva Rl, Chung $Y$, Hwang $D$, Yang $X O$, Kang $H S$, Ma L, Wang $Y H$, Watowich SS, Jetten AM, Tian Q, et al. Generation of T follicular helper cells is mediated by interleukin-21 but independent of Thelper 1, 2, or 17 cell lineages. Immunity. 2008;29(1):138-49.

33. Yan L, de Leur K, Hendriks RW, van der Laan LJW, Shi Y, Wang L, Baan CC. $T$ follicular helper cells as a new target for immunosuppressive therapies. Front Immunol. 2017;8:1510.

34. Jiang H, Cui N, Yang L, Liu C, Yue L, Guo L, Wang H, Shao Z. Altered follicular helper $T$ cell impaired antibody production in a murine model of myelodysplastic syndromes. Oncotarget. 2017;8(58):98270-9.

35. Xie X, Mu L, Yao X, Li N, Sun B, Li Y, Zhan X, Wang X, Kang X, Wang J, et al. ATRA alters humoral responses associated with amelioration of EAMG symptoms by balancing Tfh/Tfr helper cell profiles. Clin Immunol (Orlando, Fla). 2013;148(2):162-76.

36. Pandya JM, Lundell AC, Hallstrom M, Andersson K, Nordstrom I, Rudin A Circulating $T$ helper and $T$ regulatory subsets in untreated early rheumatoid arthritis and healthy control subjects. J Leukoc Biol. 2016;100(4):823-33.

37. Ma CS, Avery DT, Chan A, Batten M, Bustamante J, Boisson-Dupuis S, Arkwright PD, Kreins AY, Averbuch D, Engelhard D, et al. Functional STAT3 deficiency compromises the generation of human $\mathrm{T}$ follicular helper cells. Blood. 2012;119(17):3997-4008.

38. Eddahri F, Denanglaire S, Bureau F, Spolski R, Leonard WJ, Leo O, Andris F. Interleukin-6/STAT3 signaling regulates the ability of naive T cells to acquire B-cell help capacities. Blood. 2009;113(11):2426-33.

39. Wang M, Wei J, Li H, Ouyang X, Sun X, Tang Y, Chen H, Wang B, Li X. Leptin upregulates peripheral CD4(+)CXCR5(+)|COS(+) T cells via increased IL-6 in rheumatoid arthritis patients. J Interf Cytokine Res. 2018;38(2):86-92.

40. Deng J, Fan C, Gao X, Zeng Q, Guo R, Wei Y, Chen Z, Chen Y, Gong D, Feng $J$, et al. Signal transducer and activator of transcription 3 hyperactivation associates with follicular helper $\mathrm{T}$ cell differentiation and disease activity in rheumatoid arthritis. Front Immunol. 2018;9:1226.

41. Schmitt N, Bentebibel SE, Ueno H. Phenotype and functions of memory Tfh cells in human blood. Trends Immunol. 2014;35(9):436-42.

\section{Ready to submit your research? Choose BMC and benefit from:}

- fast, convenient online submission

- thorough peer review by experienced researchers in your field

- rapid publication on acceptance

- support for research data, including large and complex data types

- gold Open Access which fosters wider collaboration and increased citations

- maximum visibility for your research: over $100 \mathrm{M}$ website views per year

At BMC, research is always in progress.

Learn more biomedcentral.com/submissions 